\title{
The effectiveness of polymer adhesive in reduction of vibrations of structural members
}

\author{
Natalia Lasowicz ${ }^{1,{ }^{*}}$, Arkadiusz Kwiecień ${ }^{2}$, and Robert Jankowski ${ }^{1}$ \\ ${ }^{1}$ Gdansk University of Technology, Faculty of Civil and Environmental Engineering, 11/12 \\ Narutowicz St., 80-233 Gdańsk, Poland \\ ${ }^{2}$ Cracow University of Technology, Institute of Structural Mechanics, 24 Warszawska St., 31-155 \\ Cracow, Poland
}

\begin{abstract}
In this paper, the idea of using polymer adhesive as a damping layer is proposed. An experimental study of two aluminium cantilevered beams has been conducted. One of them presents a plain cantilevered beam, while the second one considers two aluminium beams bonded with a polymer adhesive of different thickness $(0,5 ; 1,2 ; 1,75 ; 3,1$ and $5 \mathrm{~mm})$. The polymer adhesive considered in the study is a specially designed flexible two-component grout, which has high damping properties. The aim of the study is to determine dynamic parameters, such as natural frequencies and damping ratios of both beams, based on the tests in which analyzed elements have been induced to vibrations by a modal hammer. The behaviour of the beams under different additional weight, installed at the end of elements, has been studied. The results of the study clearly show that the response of the composite aluminium beam with polymer adhesive inside is substantially different then the response of the plain beam. The application of polymer adhesive leads to significant increase in structural damping. Based on the results, the method of using the polymer adhesive can be considered as an effective one in reduction of structural vibrations.
\end{abstract}

\section{Introduction}

The presence of dynamic loads caused by wind, earthquake or crowd load effect generates structural vibrations that can be dangerous to the strength and stability of civil engineering structures (see for example [1-3]). The design of structures resistant to such kind of loads is really problematic. If the induced vibration excites a natural frequency of the affected part of the structure, resonance might occur. It may lead to severe damages of civil engineering structures, their collapse or panic among the people [4-7]. The most popular method to reduce structural vibrations generated by dynamic effects is to install additional stiffening elements to increase the overall structural dynamic resistance [8]. Nowadays, also other approaches aiming to reduce structural vibrations are used, for example application of additional elements so as to increase dissipation of energy during excitations (see also [9$11])$.

\footnotetext{
*Corresponding author: natmajew@pg.edu.pl
} 
In this paper, an idea of using polymer adhesive as a damping layer is considered. An experimental study of two aluminium cantilevered beams has been conducted. One of them presents a plain aluminium cantilevered beam, while the second one considers two aluminium beams bonded with a polymer adhesive of different thickness $(0,5 ; 1,2 ; 1,75 ; 3,1$ and $5 \mathrm{~mm}$ ). The polymer adhesive considered in the study is a specially designed flexible two-component grout, which has high damping properties [12, 13].

The aim of the study is to determine the effectiveness of polymer adhesive in reduction of structural member vibrations. Dynamic parameters, such as natural frequencies and damping ratios have been calculated for both cantilevered beams, based on the tests in which analyzed elements have been induced to vibrations by a modal hammer. Moreover, the behaviour of the beams under different additional weight, installed at the end of elements, has been studied.

\section{Experimental study}

Two aluminium cantilevered beams have been tested. One of them describes a plain cantilevered beam, while the second one present composite beam consisting of two aluminium beams bonded with polymer adhesive of different thickness $(0.5 ; 1.2 ; 1.75 ; 3.1$; $5 \mathrm{~mm}$ ). Aluminium beam, that was a subject in the study, has a total length of $1.25 \mathrm{~m}$, width of $0.03 \mathrm{~m}$ and thickness of $0.009 \mathrm{~m}$. A scheme of composite cantilevered beam has been presented in Figure 1.

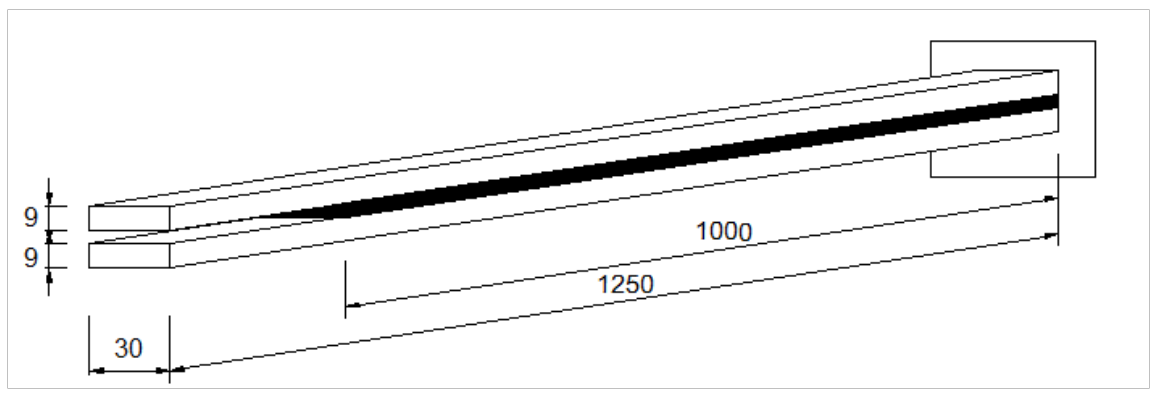

Fig. 1. A scheme of composite cantilevered beam with polymer adhesive.

The aim of an experimental study was to analyze the response of aluminium cantilevered beams subjected to dynamic loads generated by modal hammer. The first stage of the study concerns the estimation of modal characteristics for the plain aluminium beam as well as for beam with polymer adhesive inside. Both models of beams have been excited by impacts of modal hammer applied at the middle of the elements length. The behaviour of the beams has been observed and recorded by two accelerometers. Moreover, an additional mass has been applied at their ends $(3.5$ and $6.0 \mathrm{~kg})$ and the response of a plain and composite cantilevered beams has been analyzed. Total time duration of each measurement was equal to 12.5 seconds.

As the results from experimental study modal characteristics, such as natural frequencies of vibration modes and damping ratios have been determined. A large number of tests have been conducted. The results of the experimental study have been presented in the form of acceleration time histories, based on which modal characteristics have been obtained. Representative acceleration time histories describing the behaviour of plain and composite aluminium cantilevered beams with additional weight of $3.5 \mathrm{~kg}$ have been presented in Figure 2-5. Values of natural frequencies calculated for both aluminium cantilevered beams are summarized in Table 1 . 


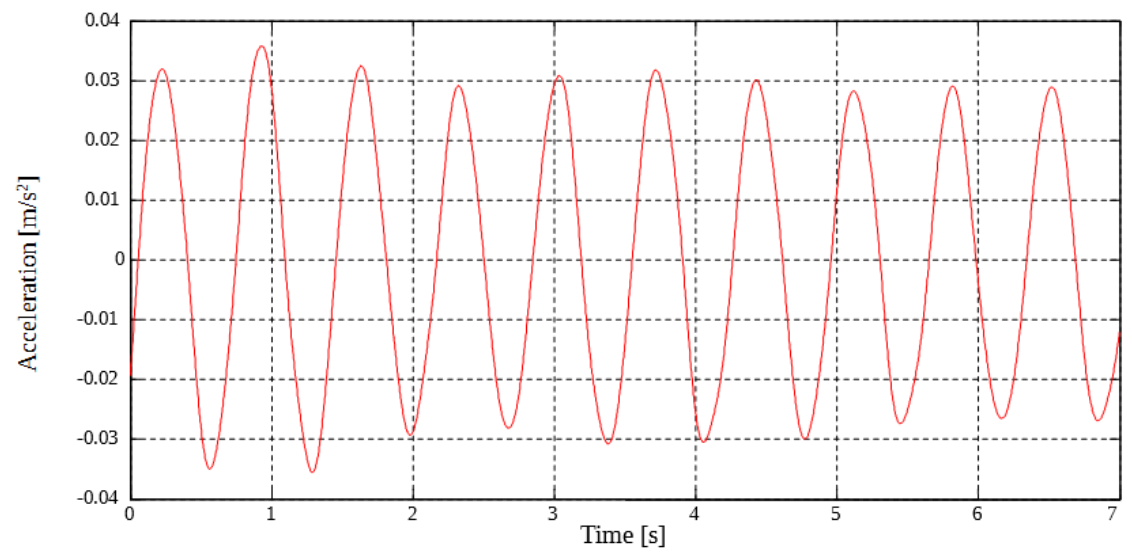

Fig. 2. Acceleration time history of a plain aluminium cantilevered beam (weight $3.5 \mathrm{~kg}$ ).

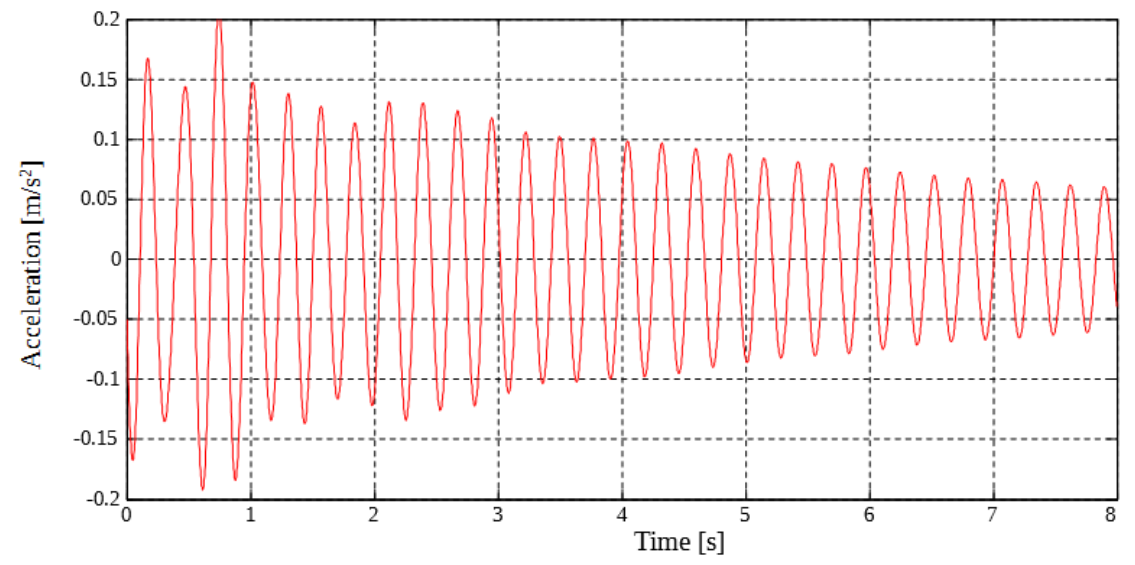

Fig. 3. Acceleration time history of a composite cantilevered beam with polymer adhesive of thickness $0.5 \mathrm{~mm}$ (weight $3.5 \mathrm{~kg}$ ).

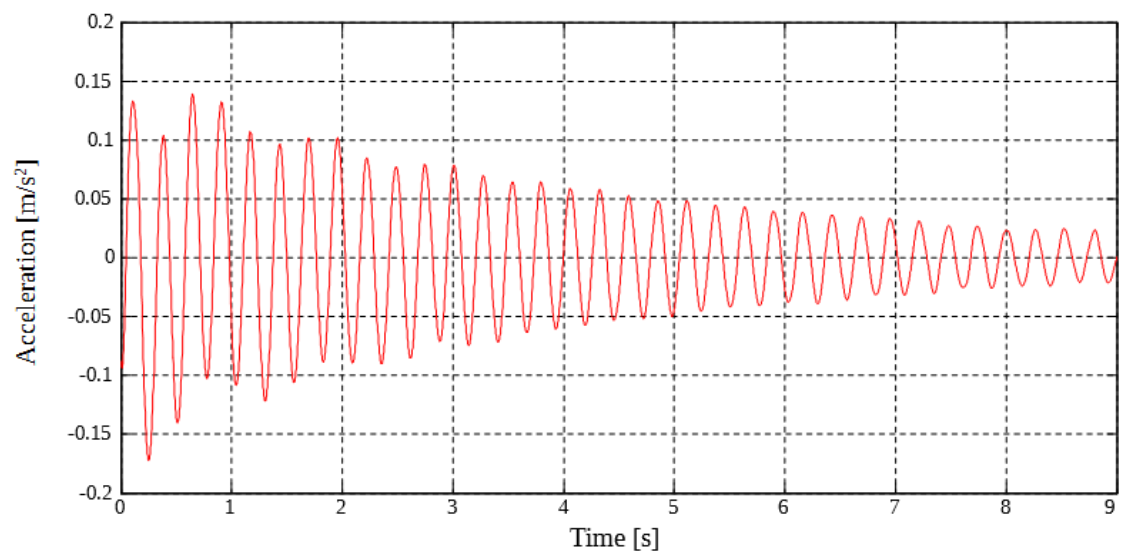

Fig. 4. Acceleration time history of a composite cantilevered beam with polymer adhesive of thickness $1.2 \mathrm{~mm}$ (weight $3.5 \mathrm{~kg}$ ). 


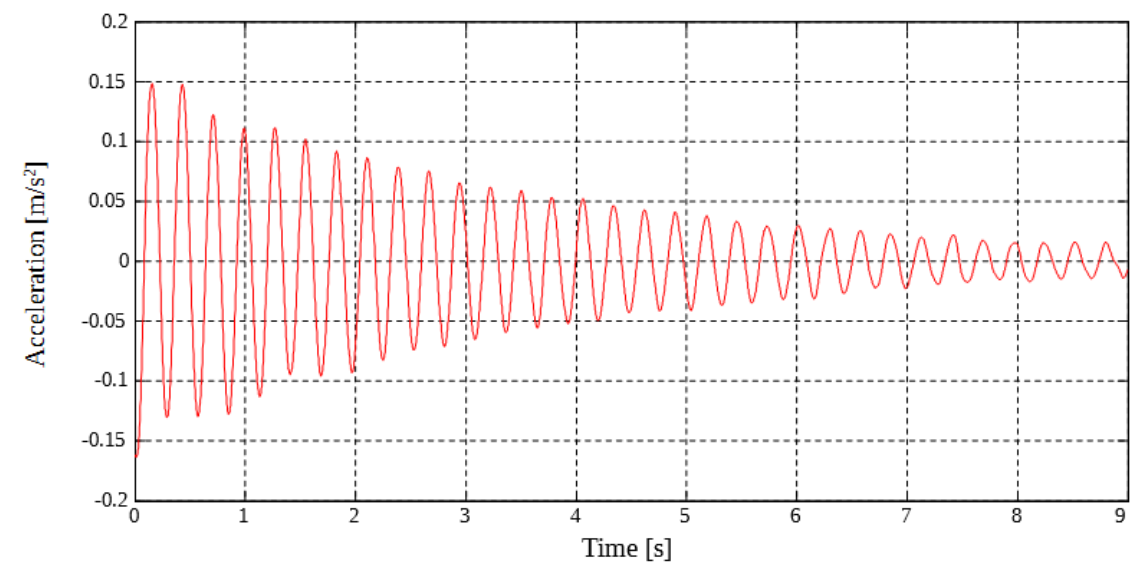

Fig. 5. Acceleration time history of a composite cantilevered beam with polymer adhesive of thickness $5 \mathrm{~mm}$ (weight $3.5 \mathrm{~kg}$ ).

Table 1. Natural frequencies estimated for both models of aluminium cantilevered beams under additional weight.

\begin{tabular}{|c|c|c|c|c|c|c|}
\hline \multirow{2}{*}{$\begin{array}{c}\text { Weight } \\
{[\mathrm{kg}]}\end{array}$} & \multicolumn{5}{|c|}{$\begin{array}{c}\text { Plain } \\
\text { aluminium } \\
\text { beam }\end{array}$} & \multicolumn{5}{|c|}{$\begin{array}{c}\text { Composite beam with polymer adhesive } \\
\text { of different thickness }\end{array}$} \\
\cline { 3 - 7 } & $\begin{array}{c}0.5 \\
\mathrm{~mm}\end{array}$ & $\begin{array}{c}1.2 \\
\mathrm{~mm}\end{array}$ & $\begin{array}{c}1.75 \\
\mathrm{~mm}\end{array}$ & $\begin{array}{c}3.1 \\
\mathrm{~mm}\end{array}$ & $5 \mathrm{~mm}$ \\
\hline 0 & 4.00 & 7.70 & 8.30 & 8.20 & 8.00 & 7.55 \\
\hline 3.5 & 1.50 & 3.53 & 3.70 & 3.70 & 3.70 & 3.50 \\
\hline 6.0 & 1.30 & 2.82 & 2.97 & 3.00 & 3.00 & 2.80 \\
\hline
\end{tabular}

It can be seen from Table 1 that adding of weight to the cantilever structure causes shifting of natural frequencies to lower value. The maximum shift equal to $68 \%$ has been observed in case of plain aluminium cantilevered beam. It should be underlined that application of polymer adhesive leads to substantial increase in natural frequency (by as much as $110 \%$ in the case of composite beam with polymer adhesive of thickness $1.2 \mathrm{~mm}$ comparing with a plain aluminium beam). Also changes of geometry of analyzed beams have an influence on frequency shifting. There is no significant difference between values of natural frequency determined for composite cantilevered beam with polymer adhesive of different thickness. The maximum difference obtained from experimental study was equal to $9 \%$. Another dynamic parameter such as damping ratio for aluminium cantilevered beams has been calculated based on Fast Fourier Transform Analysis. Damping ratio have been determined from frequency domain using Half-Power Bandwidth Method and summarized in Table 2 . 
Table 2. Damping ratio estimated for both models of aluminium cantilevered beams under additional weight.

\begin{tabular}{|c|c|c|c|c|c|c|}
\hline \multirow{3}{*}{$\begin{array}{l}\text { Weight } \\
{[\mathrm{kg}]}\end{array}$} & \multicolumn{6}{|c|}{ Damping ratio $[\%]$} \\
\hline & \multirow{2}{*}{$\begin{array}{l}\text { Plain } \\
\text { aluminium } \\
\text { beam }\end{array}$} & \multicolumn{5}{|c|}{$\begin{array}{l}\text { Composite beam with polymer adhesive } \\
\text { of different thickness }\end{array}$} \\
\hline & & $\begin{array}{c}0.5 \\
\mathrm{~mm}\end{array}$ & $\begin{array}{c}1.2 \\
\mathrm{~mm}\end{array}$ & $\begin{array}{l}1.75 \\
\mathrm{~mm}\end{array}$ & $\begin{array}{l}3.1 \\
\mathrm{~mm}\end{array}$ & $5 \mathrm{~mm}$ \\
\hline 0 & 0.17 & 0.76 & 0.72 & 0.98 & 1.31 & 1.01 \\
\hline 3.5 & 0.37 & 0.60 & 0.84 & 0.94 & 1.09 & 1.31 \\
\hline 6.0 & 0.19 & 0.55 & 0.97 & 0.92 & 1.29 & 1.49 \\
\hline
\end{tabular}

As it can be seen from Table 2 application of polymer adhesive leads to substantial increase in values of damping ratio of composite cantilevered beam. In the case of application of polymer adhesive of a thickness equal to $5 \mathrm{~mm}$, value of damping ratio increased by $254 \%$ (additional weight $3.5 \mathrm{~kg}$ ) and $684 \%$ (additional weight $6 \mathrm{~kg}$ ).

\section{Conclusions}

In this paper the response of aluminium cantilevered beams has been conducted through experimental study. Effectiveness of application of polymer adhesive, that bonds two aluminium cantilevered beams, in reduction of structural vibrations has been considered. The experiment has been conducted so as to determine values of natural frequencies and damping ratios for the cantilevered beams without and with polymer adhesive with additional weight.

The results of the study have confirm that application of polymer adhesive may lead to even ten times higher values of damping ratio. Therefore, the method can be considered as an effective one in reduction of structural vibrations..

\section{References}

[1] E. Simiu, R. Scanlan, Wind Effects on Structures, Third edition (John Wiley and Sons, USA, 1996)

[2] R. Jankowski, S. Mahmoud, Earthquake-Induced Structural Pounding (Springer, Cham, Switzerland, 2015)

[3] B. R. Ellis, T. Ji, J. D. Littler, Structures and Buildings, 140, 4, 355-365 (2000)

[4] V. Brito, R. L. Pimentel, Journal of Performance of Constructed Facilities, 23, 3, 151-159 (2009)

[5] R. Jankowski, S. Mahmoud, Bulletin of Earthquake Engineering, 14, 3075-3097 (2016)

[6] H. Naderpour, R. C. Barros, S.M. Khatami, R. Jankowski, Shock and Vibration, 2016, article ID 1504783 (2016)

[7] T. Falborski, R. Jankowski, Procedia Engineering, 172, 277-283 (2017)

[8] P. Błażejewski, J. Marcinowski, Zeszyty Naukowe Politechniki Rzeszowskiej, Budownictwo i Inżynieria Środowiska, 58-3/11/II, 209-216 (2011) 
[9] N. Lasowicz, A. Kwiecień, R. Jankowski, Journal of Physics: Conference Series, 628, 17 (2015)

[10] T. Falborski, R. Jankowski, Applied Sciences 8(3), 400 (2018)

[11] T. Falborski, R. Jankowski, Applied Sciences 7(8), 808 (2017)

[12] A. Kwiecień, Flexible polymer adhesives versus stiff mineral and epoxy adhesives tested dynamically on masonry columns strengthened using of bonded GFRP mesh, Proceedings of 8th International Conference on Structural Dynamics, Belgium 2011

[13] N. Lasowicz, A. Kwiecień, R. Jankowski, Key Engineering Materials 624, 478-485 (2015) 